\title{
COMMENTARY
}

\section{Achieving Enrollment Outcomes by Aligning Applicant Recruitment and Selection with Unique Organizational Niches}

\author{
Jeremy A. Hughes, PharmD, EdDc, ${ }^{a}$ Helen C. Park, PharmD, ${ }^{b}$ Dustin Christensen-Grant, PharmD, \\ David G. Fuentes, PharmD, MSOL, EdDc $c^{\mathrm{c}, \mathrm{d}}$ \\ ${ }^{a}$ Chicago State University, College of Pharmacy, Chicago, Illinois \\ ${ }^{\mathrm{b}}$ Roseman University of Health Sciences, Henderson, Nevada \\ ${ }^{\mathrm{c}}$ University of Portland, School of Nursing, Portland, Oregon \\ ${ }^{\mathrm{d}}$ Editorial Board Member, American Journal of Pharmaceutical Education, Arlington, Virginia
}

Submitted June 25, 2019; accepted December 15, 2020; published April 2021.

\begin{abstract}
Several Doctor of Pharmacy programs have rescinded their requirement for applicants to complete the Pharmacy College Admissions Test, modified their requirements for prerequisite coursework, and reduced the minimum grade point average required for admission. As schools and colleges of pharmacy begin to use these and other more holistic approaches to recruitment and admission, the quantity and quality of students in the applicant pool will continue to shift. In alignment with their unique mission, values, and vision statements, pharmacy programs have also expanded aspects of their application and review process to increasingly focus on applicants' leadership skills, community service, teamwork, collaboration skills, and paid and volunteer work. These aspects allow them to look beyond a candidate's academic performance and instead emphasize skills and affective domain areas that are aligned with the Accreditation Council for Pharmacy Education standards and Center for the Advancement of Pharmacy Education outcomes. Ways in which pharmacy schools and colleges can refine their recruitment and admissions processes to better align with their unique curricular and programmatic niche areas are discussed.
\end{abstract}

Keywords: admissions, matriculation, application, progression, holistic

\section{INTRODUCTION}

As the number of Doctor of Pharmacy (PharmD) applicants has steadily declined every year since 2012 while the number of PharmD programs in the United States has continued to increase (currently 144), the ratio of applicants to seats has decreased to $1.002{ }^{1}$ Students are applying to fewer institutions ( 2.6 programs per applicant) as they understand they now have a strong advantage and a greater likelihood of obtaining admission at their school of choice. In response to this shift, schools need to adapt their mindset to strategically and authentically focus on the special niche areas within their program and other aspects that differentiate their school to better ensure they attract students who will enjoy and stay in the program as well as thrive academically and, ultimately, professionally.

\section{DISCUSSION}

There are numerous differences between PharmD programs in the United States, including in length,

Corresponding Author: Jeremy A. Hughes, Chicago State University, College of Pharmacy, 9501 S. King Dr./DH 3070, Chicago, IL 60628. Tel: 773-821-2782. Email: jhughe23@ csu.edu location, curricular delivery, organizational values, areas of academic emphasis, stackable and dual-credential focus areas, and mission to serve specific patient populations. To gain a competitive advantage by capitalizing on niche areas and unique institutional branding, programs need to be mindful about marketing, messaging, and application processes to successfully attract those students who will be the best fit for their program. Information on program-specific elements, such as instructional methodology, program mission, and institutional culture, should be intentionally layered and presented through various interactions with applicants. ${ }^{2}$ These elements comprise the organizational brand and serve to create a psychological contract with applicant expectations. The degree of alignment between what a program offers and what applicants expect can be assessed using several outcomes, including student academic success, retention, engagement, and satisfaction with the program. ${ }^{3}$

Conversations between program and applicants have begun to become more program specific, which helps candidates get a better feel for the student experience at a program. Such strategies allow students to better identify 


\section{American Journal of Pharmaceutical Education 2021; 85 (4) Article 7743.}

and determine the type of program, expectations, and academic environment that best align with their preferences and strengths. Academic philosophy is becoming an important indicator of a program's uniqueness. Programs are highlighting flipped classrooms, team-based learning, team-based projects and activities, simulation of learning methodology, additional experiential learning, specialized tracks, and dual and joint degree programs. ${ }^{7}$ While many of the experiences across pharmacy programs are similar, the sequences, structure, scope, and focus of the pharmacy curricula vary widely between schools. Intimately connected to the curriculum, cocurricular elements will also need to be increasingly highlighted to help students gain a better appreciation of student life at both the institution and the cities and towns surrounding the institution. Schools will increasingly need to make use of their connections to both current and past students, developing a rich network of support in ways that make the surrounding community a holistic and immersive ecosystem in which students can build their skills, networks, and future careers.

Measures that a school could use to assess whether a candidate would be a good fit for their program and academically successful include assessments of grit, emotional intelligence, moral agency, personal strengths, and preferences, as well as assessments of writing skills and problem-solving abilities. ${ }^{4,5}$ Many programs have added such assessment to on-site interviews and/or require them as earlier parts of the admissions process such as supplemental applications and essay questions. Other institutions have modified their interview practices, including scoring candidates on multiple domains during the on-site interview and using more robust tools to assess applicants' communication and interpersonal skills. Some institutions are using Multiple Mini Interviews and other methods to evaluate applicants' reaction to various clinical and nonclinical interpersonal situations and their ability to maintain calm in the face of challenges and/or to de-escalate a difficult situation. ${ }^{6}$

These additional assessments have the potential to create barriers for applicants, particularly first-generation college students, underrepresented minorities, and others who may not be as familiar with the process of applying to professional degree programs. Programs are seeking to address imbalances created by the use of standardized examination scores and other metrics that have the potential to favor students from more affluent backgrounds and those who attended more academically prestigious institutions for their undergraduate work. Many programs have made taking the Pharmacy College Admissions Test (PCAT) optional, while others no longer include PCAT scores in admissions decisions. Most programs have already eliminated the requirement for candidates to have completed a bachelor's degree and instead focus more on the prerequisite coursework they have completed. These changes were designed to reduce barriers to applying and to open to doors for traditional and nontraditional pharmacy school applicants.

The transition from undergraduate to professional coursework can be difficult for any student, particularly for those with lower levels of academic preparedness. Pharmacy schools will increasingly need to examine and assess reasons for students having academic difficulty for attrition in both the first professional year and beyond within their program. Programs will also have to consider the challenges students face in accessing undergraduate education and completing prerequisite coursework at community colleges or less prestigious institutions while taking care of their family and addressing competing priorities such as work and school. ${ }^{8}$ Students may have one or more markers that are associated with lower levels of academic preparedness, including the institution they attended to complete prerequisite courses; grade point averages (GPAs), including cumulative and course specific; degree completion status; and standardized test scores. ${ }^{9}$ Other markers may be related to background, including socioeconomic status, first-generation college student (or professional student), rural location, and English as a second language. ${ }^{10}$ Communication abilities such as listening, writing, and speaking, and presentation skills can also be tied to student performance. ${ }^{11}$

After being accepted, increasing applicant readiness before starting PharmD coursework can ease their transition into the program. Schools may have to explore new methods for accomplishing this, such as delivering PharmD-related materials and modules online or via live platforms, and providing optional and/or required enrichment activities for incoming students to engage in. ${ }^{12}$ These readiness "boot camps" allow students to receive concentrated educational materials and engage in activities that mirror what they will do in the classroom, as well as increase their self-efficacy, confidence, and exposure to pharmacy. Prior to students starting class, schools can focus on learner specific factors, including preferred learning strategies and developing self-awareness. Content specific factors can also be addressed, including reviewing prerequisite course materials and receiving an introduction to concepts traditionally residing within the first year of the PharmD program. Programs could consider extending conditional offers of acceptance to students with lower GPAs or markers of lower levels of preparedness, with admissions being contingent on students completing these types of activities as required coursework before starting the program. Distinctions will 


\section{American Journal of Pharmaceutical Education 2021; 85 (4) Article 7743.}

need to be made between these pre-matriculation programs and post-baccalaureate programs, which typically require additional tuition, delayed start, and no guarantee of acceptance.

Making modifications to the orientation process, which has historically focused on welcoming new students and providing them with information about the institution's policies and resources, can aid in supporting students as they adjust to the rigor of a professional program. ${ }^{13}$ To promote development in the affective domain earlier in the program, some institutions have added components to the orientation process, such as personality assessments and assessments of baseline pre-requisite knowledge, to help students gain better self-awareness. ${ }^{14}$ Programs can also use the orientation period to foster relationships between students and between students and faculty mentors, thereby improving students' feelings of being supported and belonging, which have been shown to aid in student retention. Expanding both the time allotted for and content of the orientation process can be accomplished by using online modules for development and readiness assessment in the weeks leading up to the start of the first professional year. Completion of these modules can also serve as a measure of student engagement and help predict matriculation. ${ }^{15}$

Students need to be exposed to pharmacy careers before they enter higher education in order for the Academy to rebuild a healthy applicant pipeline. It is important for programs to continue working with Academy on new recruitment and marketing strategies, including the Pharm4Me campaign that targets undergraduate students as well as middle and high school students. ${ }^{16}$ Sharing these resources with undergraduate institutions, healthcare associations, and other potential partners is critical so that the pharmacy profession can increase the output of a consistent message to the public about what pharmacists do and what they are capable of doing because of the advanced education and specialized training they receive. Relationships between programs and potential students can be fostered over time, with applicants learning more about program specific differences as they gain increased exposure to academic and healthcare environments.

\section{CONCLUSION}

Making changes to their admissions and onboarding processes can be valuable steps for pharmacy schools to take to increase the total number of applicants and increase the academic readiness of students, which will position them for success in the PharmD program and in their future pharmacy careers. Schools and colleges of pharmacy should expand their efforts to increase high school and undergraduate students' awareness of pharmacy and the many roles of pharmacists as this will encourage them to consider pharmacy as a career and thereby increase the number of applicants to PharmD programs.

\section{REFERENCES}

1. American Association of Colleges of Pharmacy. 2012 American Association of Colleges of Pharmacy Annual Report. Am J Pharm Educ. 2012;76(10):Article S25.

2. Rupp MT. Branding a college of pharmacy. Am J Pharm Educ. 2012;76(9):166. DOI:10.5688/ajpe769166.

3. Desselle S, Rosenthal M, Holmes ER, Andrews B, Lui J, Raja L. Components of a measure to describe organizational culture in academic pharmacy. Am J Pharm Educ. 2017;81(10)Article 6022. 4. Romanelli F, Cain J, Smith KM. Emotional intelligence as a predictor of academic and/or professional success. Am J Pharm Educ. 2006;70(3):Article 69.

5. Kelsch MP, Friesner DL. The health sciences reasoning test in the pharmacy admissions process. Am J Pharm Educ. 2014;78(1):Article 9.

6. Heldenbrand SD, Flowers SK, Bordelon BJ, et al. Multiple miniinterview performance predicts academic difficulty in the PharmD curriculum. Am J Pharm Educ. 2016;80(2):Article 27.

7. Crass RL, Romanelli F. Curricular reform in pharmacy education through the lens of the Flexner Report of 1910. Am J Pharm Educ. 2018;82(7):Article 6804.

8. Mangione RA, Duncan WC, Johnson MS, et al. Report of the 2014-2015 AACP Standing Committee on Advocacy: access, affordability and accountability: academic pharmacy's approaches and challenges in addressing issues of higher education policy. Am J Pharm Educ. 2015;79(8):Article S14.

9. Conn KM, Birnie C, McCaffre D, Brown J. The relationship between prior experiences in mathematics and pharmacy school success. Am J Pharm Educ. 2018;82(4):Article 6257.

10. Cavanaugh NE, Hagemeier NE, Kumar K, et al. Breaking down barriers to pharmacy graduate education: the report of the 2017-2018 Research and Graduate Affairs Committee. Am J Pharm Educ. 2018; 82(7):Article 7147.

11. Parmar JR, Tejada FR, Lang LA, Purnell M, Acedera L, Ngonga F. Assessment of communications-related admissions criteria in a three-year pharmacy program. Am J Pharm Educ. 2015;79(6):Article 86.

12. Elliot RA, McDowell J, Marriott JL, Calandra A, Duncan G. A pharmacy preregistration course using online teaching and learning methods. Am J Pharm Educ. 2009;73(5):Article 77.

13. Poirier TI, Santanello CR, Gupchup GV. A student orientation program to build a community of learners. Am J Pharm Educ. 2007; 71(1):Article 13.

14. Bloom TJ, Smith JD, Wesley R. Impact of pre-pharmacy work experience on development of professional identity in student pharmacists. Am J Pharm Educ. 2017;81(10):Article 6141. 15. Klausner, EA, Rowe EL, Hamilton BS, Mark KS. Implementation, revisions, and student perceptions of a prematriculation program in a school of pharmacy. Am J Pharm Educ. 2019;83(7):7021. DOI: https//doi.org/10.5688/ajpe7021 16. Adams JL, Law A. Strategic plan priority 1: enriching the applicant pipeline. Am J Pharm Educ. 2017;81(1):Article S1. 